\section{Przegląd Badań Edukacyjnych Educational Studies Review}

ISSN $1895-4308$

nr 29 (2/2019), s. 155-175
METODY ZBIERANIA

I ANALIZY DANYCH

W BADANIACH

EDUKACYJNYCH

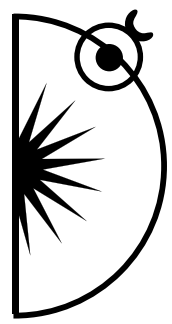

Justyna Pilarska

ORCID: 0000-0002-5646-597X

University of Wroclaw; e-mail: justyna.pilarska@uwr.edu.pl

\title{
In Pursuit of Empowering the Culturally Fragile - an Emic Approach and Indigenous Methodology in a European Research Context
}

http://dx.doi.org/10.12775/PBE.2019.022

\begin{abstract}
This article was inspired by my long-standing experience in conducting field research in the culturally diverse environment of Bosnia-Herzegovina. It contributes to the better understanding of emic research, reviewing indigenous strategies and the importance of increasing the researcher's cultural sensitivity and awareness of the cultural peculiarities they wish to investigate, through the adaptation of qualitative methods. Moreover, the article adds to the ways in which research projects are designed, acknowledging the equal status of the participants (neither the respondents nor "the researched") who can (and should) be approached ethically and with full recognition of their status as the co-producers of knowledge. Such an outlook towards one's own project can provide an important input to the emancipation and recognition of culturally fragile groups, such as ethnic or religious minorities, refugees, groups subject to social exclusion, etc. The lessons I have learned in the course of almost 17-years experience of doing field research in a multicultural setting (Bosnia-Herzegovina), also including some failures in this regard, inspired me to propose this paper as a starting point of a broader debate on conducting socially and ethically responsible field research in a multicultural society, or amongst culturally diverse groups.
\end{abstract}

Key words: emic approach, indigenous methodology, qualitative methods, multicultural society, Bosnia-Herzegovina. 


\section{Introduction}

This article is written from a European (female) scholar's standpoint, as articulated by an intercultural pedagogue. Yet, my standpoint is formed and informed by local, idiographic ways of perceiving and experiencing the social, cultural and political reality of the Muslims, Croats and Serbs from Bosnia-Herzegovina. Moreover, my perspective is particularly forged by the experience from a field research I have been conducting there since 2001 and which has taught me a greater awareness and sensitivity to a myriad of cultural peculiarities, nuances and shades that change the perception of various cultural, social or even political phenomena occurring in such a multicultural environment.

Bosnia-Herzegovina provides a unique example of a contemporary European culturally diverse society embracing the representatives of Balkan, (Ottoman) Muslim, Orthodox Church (Serbian) and Catholic (Croatian) cultural traditions saturated with the features of global mass culture and at large European lifestyles. My yearlong observations have shown the predominance of objectifying practices towards the "researched", particularly in such culturally sensitive areas as the post-war Bosnia-Herzegovina. It has led me to the realization that, very often, the research proceedings carried out by Western European scholars in Bosnia serve the purpose of confirming their implicit, albeit erroneous, assumption that they know (better than the Bosnian themselves) the ways that Bosnian multiculturalism works.

The article puts an emphasis on the role of research participants and the researcher, as well as knowledge generation in a reciprocal and constructive fashion. The impulse behind tackling such an issue also came from the strong need to oppose the attitude, still present within academia, of "disciplining the colonized", in a manner encapsulated by Michael Foucault "they came, they saw, they named, they claimed" (Foucault, 1997, p. 83). One of my objectives in this article is to argue for the important role of the emic approach within an indigenous framework, capable of incorporating decolonizing methods, and generating new knowledge through different models of inquiry to those used in Western philosophy, breaking down the power hierarchy between the researcher and the participant in ways that challenges dominant perspectives (Bishop, 1999).

For the purpose of this article I would also like to clearly define the "culturally fragile" participants of the research, and "culturally sensitive" researchers. The "culturally fragile" refers to members of culturally diverse (multicultural) communities living in ethnically, nationally or religiously diverse societies, that 
are subject to marginalization due to their minority status or any form of social, cultural, political, educational or civic underprivileged position. On the other hand, the "culturally sensitive" researcher is one aware of entering the area of interactions with such "fragiles", therefore possessing a number of interpersonal skills enabling trust, openness and reciprocity; to recall empathy, a judgment-free attitude, kindness, recognition for others, active listening, managing and recognizing one's own and others' emotions, self-awareness, and cognitive flexibility.

\section{Towards emancipation of knowledge}

As early as the 1960 s, in his article "Whose side are we on?"American sociologist Howard S. Becker (1967) suggested that, while approaching culturally sensitive groups in a research project, it is crucial to apply techniques and methods exclusively of a qualitative nature, as they are non-structured, flexible and rely on the direct contact and relationship between the researcher and the community members they wish to get to know empirically. Given the four alternative knowledge claim positions as proposed by John Creswell (2003, pp. 6-13), i.e. post-positivism, constructivism, advocacy (participatory) and pragmatism, such culturally sensitive, emic and indigenous methodology embraces, on the one hand, the advocacy paradigm, which, emancipatory in its nature is collaborative, change- and empowerment issue-oriented, and on the other, it concerns constructive knowledge claims, as in such a stance the goal of the research is 'to rely as much on the participants' views of the situation being studied" (Creswell, 2003, p. 8), whereas the researcher's intent is to "make sense of (or interpret) the meaning others have about the world" (Creswell, 2003, p. 9). Such an approach allows the participants to speak in their own voices, not confined to the categories imposed by the researcher, so that mutual engagement can provide additional benefits to the communities. This, in turn, facilitates the process of empowerment as, thanks to such a course of the research interaction, those "normally" unheard can gain subjectivity through speaking their voices - metaphorically and literally. Moreover, some groups in a culturally diverse setting (e.g. minorities or refugees) are often stigmatized not only due to their marginalization and underprivileged status in a community, but secondary stigmatization can occur also within the research process when the previously projected image of them is not only imposed upon, but also serves as a starting point of scholarly reflections concerning their biographies leading to conceptualization of knowledge, obviously omitting their own perspective and 
opinions on issues tackling their culture, society, values, etc (cf. Liamputtong, 2007). Therefore, Becker does not ask the question as to whether the researcher is on any side, but actually he poses a rhetorical question of "on which side" she or he is on. Without such a clear definition of who I am and what my position in a research is, it is almost impossible to tackle empirically any social issue, or to understand the social reality without its analysis from a given viewpoint. Naturally, it does not prevent researchers from a biased standpoint; concurrently, it does not deprive the researcher of the reliability of their own study either. Giving voice to those unheard can significantly raise the chances for a number of positive processes such as combating social inequalities, improving life opportunities, protection and emancipation of the underprivileged groups, etc. Since the purpose of a culturally sensitive research is to acknowledge, empower and strengthen the community and minority groups, such an "involved" and socially responsible approach to one's own research design can facilitate a significant transformation, as by discovering given regularities or peculiarities it is possible - with the engagement and full participation of the community members - to stimulate a social change.

With regard to social sciences in the last decades, the omnipresent Newtonian-Cartesian paradigm has presented a view of a fixed and predictable reality within which human beings are separate from nature, whereas the entirety of the universe has been reduced to the sum of its (measurable) parts. As a consequence, generally speaking, Eurocentrism has denied the validity of other ways of understanding, for it was presumed that the scholars applying a positivist paradigm speak from an inherently superior, objective (neutral) position, strongly embedding exclusion. This article questions such an approach to social research that explores cultural worlds and their representatives. For that reason, I am deliberately using bracketing to express the people who are the subjects of the research as "the researched". Referring to them as the "participants", I put emphasis on their equal and legitimate status in the research process, significantly shaping its design and course, according to the participatory and emancipatory paradigm.

Richard Schweder, a cultural anthropologist, in his book "Thinking through cultures - Expeditions in cultural psychology" emphasised the fact that it is through culture that we think, feel, behave and manage with our reality. Thus, culture is something we use to understand the world (1991). Our way of understanding the culture and social world around us is therefore strongly shaped (if not determined) by our cultural patterns according to which we perceive, process and judge in conformity with our own cultural axiology. Indeed, there are 
many theories which are based on individualistic values reflecting the Western cultures (cf. Kim et al., 1994), yet the cultural worlds are polycentric, hence each constitutes its own "universe" of the way of understanding, experiencing, "feeling" and interpreting the world, not necessarily through the prism of Western epistemology and ontology. ${ }^{1}$ In view of this, we seem to be facing a kind of clash between the traditional philosophy of science and the rise of constructive realism. This stance is empowered by post-modern thinkers such as the Viennese philosopher of science Fritz G. Wallner, according to whom "we have to give up the claim of traditional European epistemologies of complete insight" (Wallner, 1997, p. 46). It appears particularly meaningful in view of the fact that even "interdisciplinarity is always covered, at least in Europe and in the USA, by the same conception of science because all participants are stemming from the same cultural context" (Op.cit., p. 60). Moreover, according to Linda T. Smith, "research 'through imperial eyes' describes an approach which assumes that Western ideas about the most fundamental things are the only ideas possible to hold, certainly the only rational ideas, and the only ideas which can make sense of the world, of reality, of social life and of human beings" (2012, p. 58). Since we think "through cultures", paraphrasing Franz Boas (Stocking, 1974), culturally sensitive and emancipator approach implies laying aside our Kulturbrille, and putting on a set of the local, indigenous spectacles ${ }^{2}$. Taking this into account, "it is important to look and to go to other cultures, and so reach an understanding of what one actually does in one's own culture" (Wallner, 1997, p. 60). By doing so we, as culturally sensitive researchers, encounter the unique opportunity to see the world of the researched with their own Kulturbrille, applying the principles of compassion and empathy, which could be considered to be the most missing elements not only within the academia, but at large in today's societies. Consequently, as social (cultural and educational) researchers, we could also choose to impart an ontological vision that bespeaks "humanity's wholeness and interrelatedness rather than the dichotomy of 'them and us" (Stewart-Harawira, 2005, p. 154), i.e. a vision that "advocates collectivity rather than what has become 'the normality of individuality' "(ibidem).

${ }^{1}$ Contexts of psychological notions provide an interesting example of such indigenity and "localness" of some seemingly "general" cultural (in this case specifically psychological) constructs. In East Asian culture guilt is viewed as "an important interpersonal emotion that promotes filial piety, achievement motivation, and relational closeness (Kim et al., 1994, p. 13), whereas in the Western psychoanalysis it is associated with irrational beliefs, fear or unconscious desires.

${ }^{2}$ Of course the degree to which we are able to separate our own cultural identity from ourselves in the research activity is another issue. 
As a result, researchers are committed to accept accountability for the impact of their project on the lives of the community members with whom they cooperate, upholding the personal responsibility that goes along with carrying out a research project in the community. Such an approach corresponds with the constructive realistic view that science is embedded in the cultural context. By acknowledging such stance, the idea of generalization and universalization is concurrently - questioned.

\section{The emic approach}

The emic and etic strategies were outlined originally in cross-cultural, psychological research in the 1960s by John W. Berry (Berry, 1969; 1989), who classified the research approaches of cross-cultural psychology into three categories. The first one was imposed etic, which assumed that the concepts used by a researcher can be applied to all cultures, thus corresponding to a positivist paradigm (also in line with the European-centred or westernized inquiry). The second category, i.e. emic, stressed the importance of using concepts and terms from the local cultural system, so as to understand the meanings of local phenomena; whereas, the third group, i.e. derived etic aimed at integrating the knowledge obtained by the imposed etic and emic approaches through a process of comparison $^{3}$. The emic perspective, which is the focus of the reflection in this paper, implies an exploratory attitude in gathering cultural, social and psychological data, committing the researcher to work with locally (indigenously) accepted procedures, acknowledging reflexivity as an indicator of validity within qualitative research. It advocates the thesis that suspending the use of the overriding theoretical models facilitates the discovery and full comprehension of the cultural peculiarities in the focus of the researcher's attention. Consequently, such a suspension opens up the area of applying various qualitative methods, as, according to Norman Denzin and Yvonna Lincoln, "qualitative researchers stress the socially constructed nature of reality, the intimate relationship between the researcher and what is studied, and the situational constraints that shape inquiry" (2005, p. 13). A powerful method of meeting this objective is the use of story, life story, oral history, unstructured interviews, allow participants to share their experiences in their own terms (Kovach, 2009, p. 82). Thus, in culturally

${ }^{3}$ The term 'insider research' is, therefore, something of a misnomer in these circumstances as even if the researcher belongs to the community they are researching, they are obliged, within a relationship ethics, to establish and maintain a role of a researcher (Smith, 2004). 
sensitive research, "reflexivity is a central component of the research process as it requires self-awareness in creating knowledge" (Gergen, Gergen, 2003, p. 579). The self, however, concerns not only the identity of the researcher, but equally the participants coming from the community. That is why in emic, idiographic, culturally sensitive research projects a researcher is never apart from own "reflective journal", which contains a mix of research observations, reading analysis, field notes, annotations, road trip reflections for only "critically reflective self-location gives opportunity to examine our research purpose and motive" (Kovach, 2009, p. 112).

In view of the critique that "indigenous communities are being examined by non-Indigenous academics who pursue Western research on Western terms" (Kovach, 2009, p. 28), a similar assumption can be made concerning cultural diversity within the European communities, embracing various minority groups that are "researched" by the representatives of "Western academia". The latter, in turn, often possess little knowledge on the cultural specificity of the community members, frequently objectifying (reification) their status and treating them instrumentally as informants, and "sources of knowledge". Such an approach, in consequence, deprives the culturally fragile groups of their power of control over the course of the research, pushing them to the position of the inferior parts of the researcher's project. On top of that, in such stances the ethic protocols are often infringed too ${ }^{4}$.

Emic strategy applied in the research design is therefore emancipatory for the members of the community subject to the researcher's study, as well as participatory in nature, meaning the "informant" has an input in the process in terms of defining the direction and flow of gathering data. Consequently, it acknowledges the assumption of equal status between the participant and the person gathering data. Therefore, emic strategy as well as indigenous methodologies "disrupt methodological homogeneity in research" (Kovach, 2009, p. 12) making it a "holistic, personal journey, not solely its cognitive component" (p. 15).

Before J.W. Berry categorized the types of emic and etic approaches, emic research had been tackled in the 1950s by the American linguist and anthropologist Kenneth Lee Pike in his work "Language in relation to a unified theory of the structure of human behaviour" (Pike, 1954). This concept became strongly acknowledged in the works of Clifford Geertz, in which he developed the methodology of "thick" and "thin" description. The thick description puts accent on

${ }^{4}$ For example, Aboriginal and Torres Strait Islanders were subjected to research that sought 'solutions' to Aboriginal 'problems', with these being defined by non-Aboriginals (cf. Janke, 1999). 
the interpretative nature of the cultural phenomena under investigation, recognizing the emic approach as one of the paths leading to the discoveries of given aspects of the social, cultural and psychological reality. Emic strategy is a part of the constructive and participatory (advocacy) paradigm, as it requires from the researcher to adapt a flexible, open-mined and respectful manner of approaching members of the "researched' community, assuming that knowledge is a creation of human mind, and is constantly changing. For nothing is fixed and everything is temporary; the discoveries of the research are strongly contextualized and idiographic in their nature, i.e. concerning the contingent, unique, and often subjective phenomena of the culture. Emic strategy, in other words, involves researching the cultural and social worlds from "within", and is tightly linked to:

internal organization of the culture and the language ${ }^{5}$,

1. perspective of the participant of culture;

2. participant observation with the application of the notions and distinctions specific for the member of a given community (shadowing the members of the community in their daily tasks),

3. empathy opposed to distance, the first considered as a non-intellectual means of cognition, followed by a judgment- and expectation-free state of mind,

4. meaning-making involving "observation, sensory experience, contextual knowledge [...] combined with a form of inductive analysis" (Kovach, 2009, p. 140).

Moreover, since the emic approach implies the position of an insider, it allows the researcher to gain insight into various areas of human functioning, i.e. the cognitive as well as emotional worlds of the community members, contrary to the behavioural indicators subject to quantitative or etic measurement. The latter, as the experience of some field researchers proves (XXX, 2015), serves the purpose of legitimization of the Western philosophy of science and keeping the political, as well as social, status quo, treating the cultures subject to study with an almost post-colonial superiority. The scholars conducting research in a culturally diverse setting should take into consideration a number of methodological, but at the same time ethical, questions that put upon them social

${ }_{5}^{5}$ The selection of words and the vocabulary in use matters greatly in this regard. As Paulo Freire said "name the word, name the world". 
responsibility in relation to the balance of power and control in research, given the emic approach in social research recognizes a high status of ethics within the agenda. The questions to be considered are formulated according to Linda T. Smith (1999, p. 10) and are as follows:

1. Whose research is this?

The awareness of one's own "self" in the research process, e.g. me as a female researcher from Poland in a culturally diverse Balkan society.

2. Who owns it?

The research as a process and its findings "belongs" to me as a researcher as much as to the participants who share their life experiences, viewpoints, and at times very emotional accounts of their life episodes, thus our status of the "owner" of the research design is shared through our shared emotional and interpersonal journey.

3. Whose interests does it serve?

Given the personal involvement and the culturally sensitive matter of such research design it should predominately serve not the researcher's agenda, but the local community, in conformity with the emancipatory, advocacy paradigm.

4. Who will benefit from it?

It should essentially become beneficial to those "traditionally" objectified by the positivist researchers, giving the opportunity to the members of the local cultures to grow and heal (in accordance with the Indigenous scope).

5. Who has designed its questions and framed its scope?

The research design should involve the local participants at the stage of reviewing the list of questions and in general the method of gathering data. Framing the scope should be initiated by the researcher; however its modification can occur on account of the local participants' recommendations or advice.

6 . Who will carry it out?

It should be carried out by the researcher, whose role is to manage the course of the research with an active, involved participation on the side of the local respondents and interviewees - i.e. the guides through their own cultural and social worlds.

7. Who will write it up?

It is the researcher's task, taking into account the original transcript, that conveys thick description through nuances such as dialects, selection of vocabulary in storytelling, and etc. These aspects of the gathered audio and visual data should not be altered from their original meaning in any way.

8 . How will the results be disseminated? 
In view of the emic, culturally sensitive, research agenda it is essential for researchers to disseminate research results to participants after the project is completed and data processed. They should get the feedback encapsulating the research findings, or copies of the monograph, article, or research report, and be able to make comments on that as well. The above issues constitute the core of the indigenous research agenda which, according to Smith (1999, pp. 115-118), should include healing, mobilization, transformation and decolonization on many levels. An emic approach, as an integral part of the indigenous methodology helps the researchers see the world with the eyes of the culture "bearers", breaking the approach of the "all seeing eye". Such an approach to the research participants involves qualitative methods, as they provide the appropriate conditions for collaborative, participatory and multidisciplinary research, in which an interpersonal, indispensable bond between the researcher and the participant takes place.

\section{Indigenous methodologies}

Although originally the term "Indigenous" is used to refer to the Indigenous peoples of the earth, for this article, I use it with reference to any local, culturally specific knowledge unique to a certain (also European) population, such as Bosnian Muslims in Croat-Muslim Federation, or Bosnian Serbs in Republika Srbska. Given this methodology, I consider it, however, as a practical impetus to promote a post-colonial approach in field research, questioning the Western approach to scholarship on non-Western (such as Balkan, Bosnian Muslim) cultures, which would often look into their cultures as a curiosities, without recognition of their status as legitimate bearers of knowledge on their own culture. Methodologically, it conveys idiographic, locally specific habits of perceiving and understanding the world (ontology and epistemology), axiology and general approach to the empirical investigation. Indigenous research therefore adheres to the principles of mutual trust and recognition between the researcher and the participants of the research, and offers guidelines for culturally sensitive and aware researchers.

According to Linda Smith, "some methodologies regard the values and beliefs, practices and customs of communities as 'barriers' to research or as exotic customs with which researchers need to be familiar in order to carry out their work without causing offence" (Smith, 2012, p 15), whereas indigenous methodologies tend to approach cultural protocols, values and behaviours as an 


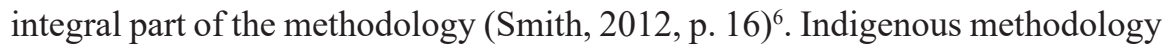
explicitly points to the emancipatory and engaging nature of the empirical investigations, of which the aim is to transform the community of research participants in terms of social, economic, political as well as psychological change, mobilizing the individuals at various levels, such as local, regional, but equally global and national, helping to heal the underprivileged and culturally fragile spiritually, socially and mentally. In order to embrace such a wide and demanding scope of research, the research has to employ specific methods of gathering data. The key features of the Indigenous methodologies entail recognition of the local community members' worldviews, their knowledge, and realities, honoring social mores through which such community, cultural or minority groups live, learn, and situate themselves, putting strong accent on the social, historical, and political contexts which shape their experiences, lives, positions, and futures (Martin et al., 2003). It is also of great importance to consider, promote and acknowledge complexity concerning the explicating ontological, epistemological, and axiological concepts that may be foreign to the Eurocentric scholarly convention (e.g. in terms of the Bosnian multiculturalism that would be the specificity of Bosnian Islam, Sufi tradition, local cultural habits related to the cultural blend of Islam, Christianity and old medieval traits of the Bosnian Church) (cf. Fine, 2007). Moreover, the Indigenous Ethics for research demand from the emic adoptee to follow the four R's principle (Chilisa, 2011, pp. 21-22), i.e.:

Respect for creating spaces for the voices of the Other and their knowledge systems.

- Relevance relating to issues members of such communities face, as reflected in the rights and regulations during the research process, thus, becoming inspired by Indigenous methodologies allows to honour cultural traditions and protocols as integral in working with the local community and its members.

${ }^{6}$ Nonetheless, it is equally important to, as Virgilio Enriquez emphasizes, distinguish between indigenization from within and indigenization from without (the latter similarly to the imposed etic approach importing Western knowledge). According to this Philippine psychologist, indigenization from within entails application of "the local languages and cultures as sources for theory, method, and praxis" (Enriquez, 1994, pp. 152-169). The indigenous methods developed in the Philippines entail, for instance, as for participant observation empathy, dalaw-dalaw (informal visiting), or more direct interaction in the culture bearer's natural habitat (Enriquez, 2006, p. 58), adopting the behaviours and ways of a particular group's as own. 
- Reciprocity also as a key feature of the interpersonal skills of the researcher.

- Relational responsibility, which implies that all parts of the research process are indeed related and that the researcher is accountable to all (Chilisa, 2011, p. 21).

Subsequently, the intention of an Indigenous approach to research, is to both decolonize the areas of collaboration and knowledge production between Indigenous and Western modes of research and to rewrite (...)the boundaries between these ways of knowing (Smith, 1999). Therefore, the descriptive words associated with Indigenous methodologies, stress the profound interconnectedness of all existence, and include: Interactional, Interrelational, Broad-based, Whole, Inclusive, Animate, Cyclical, Fluid, Spiritual (Kovach, 2009, p. 56). On top of that, the interconnectedness is also manifested with the relatedness of the researcher(s) and the participants.

An Indigenous approach to research can encompass, depending on the researcher's position, both interpretative and critical/emancipatory theories. Since "indigenous methodologies may simply be a subcategory of a Western paradigm that utilizes qualitative research approaches" (Kovach, 2009, p. 30), one of such indigenous and emic manners of gathering data is storytelling. According to Margaret Kovach, "stories are connected to knowing, (...) is both method and meaning, and is a central feature of indigenous research and knowledge methodologies" (Kovach, 2009). Thus, data collection follows what Viney (1988) ${ }^{7}$ described as the mutual-orientation model, in which both the data collector and the contributor give something to, and vice versa, gain something from the process. An interesting example in this regard concerns the indigenous Pilipino interviews (pagtatanong-tanong) (Pe-Pua, 2006, p. 115). Pagtatanong-tanong, although an idiographic phenomenon, yet manifesting essential features of an emic research strategy, has four major characteristics.

It is participatory in nature, ensuring inclusiveness in all levels of the research process; hence, the research participant contributes to the structure of the interaction in terms of defining its direction (ergo, if I am told that asking about the memories of the Bosnian war are too painful I should respect this refusal to carry on this thread of conversation) and, for instance, in time management (if the interviews are too long, too exhausting, or quite the contrary - if the participants are open and willing to prolong the scheduled conversation (interview) the researcher should be flexible and responsive to that).

\footnotetext{
${ }^{7}$ Cited in Enriquez, 1994, p. 61.
} 
1. The researcher and the participant are equal in status; this means both parties may ask each other questions for about the same length of time and content (for instance if I ask my research participant about the meaning of life or conditions which support peaceful coexistence between the ethnic groups, the ideas on the initial cause of the war, or the attitudes to nationalistic propaganda, they have the equal right to ask me the same question in order to allow a natural course of conversation); the relational emphasis should be present at all stages of conducting research. A perfect summary of the essence of the researcher's attitude and position in the Indigenous approach is expressed by saying "If researchers are humble, willing to learn, and patient doing research "with" rather than "on" Aboriginal people. They are the experts" (Kurtz, 2013. p. 226).

2. In ensuring protocols are respected and followed, such a strategy is appropriate and adaptive to the conditions of the group of participants in that it conforms to existing group norms (following daily customs accompanying informal meetings such as - in Bosnian daily culture - drinking coffee or not minding the participant smoking a cigarette, playing with children in the meantime, enjoying some food together, etc).

3. It is integrated with other indigenous research methods (adapting to local customs, being flexible with the language and even dialects, having profound knowledge on the local culture, and history - especially if it entails some war and traumatic memories - and the like).

Some interesting examples in this regard come from the Indigenous scholar Judy Atkinson (2002), who used Dadirri as a research methodology in her study, published as "Trauma Trails, Recreating Song Lines: The Transgenerational Effects of Trauma in Indigenous Australia". Dadirri is used to inform ethical behaviour in research and to help ensure cultural safety in research design (Atkinson, 2002, p.15). The principles and functions of Dadirri, as used by Atkinson, are "knowledge and consideration of community, and the diversity and unique nature that each individual brings to the community, ways of relating and acting within the community, a non-intrusive observation, or quietly aware watching, a deep listening and hearing with more than the ears, a reflective non-judgmental consideration of what is being seen and heard, and, having learnt from the listening, a purposeful plan to act, with actions informed by learning, wisdom, and the informed responsibility that comes with knowledge" (Atkinson, 2002, p. 16). Such manner of designing a research can significantly 
contribute to the participatory knowledge claims in their advocacy nature; promote feminist perspectives, anti-racialized discourses (entailing the key issues of the control and production of knowledge), disability and/or minority inquiries, addressing the issue of inclusion. In other words, it can enrich the critical theory perspective that are concerned with empowering various members of diverse cultural, social, economic and racial background in order to transcend constraints placed on them by class, gender, race, social status, the degree of disability, marginalization, and etc.

\section{Conclusions - bridging the gap}

According to Susan Boyd, "knowledge is power and the choice of methodology is a political act" (2005, p.1). Since knowledge is neither accultural nor apolitical (Kovach, 2009, p. 30), it is of paramount importance to take into consideration local, idiographic cultural, social and political phenomena, which can contribute to a given image of local cultures and social micro worlds. Moreover, acknowledging such cultural and political "origins" of knowledge, the researcher should be able to capture the given phenomena from a complex perspective, involving various angles, i.e. stemming from multiple discourses involved (such as all cultural groups, including minorities, etc). This is discernible particularly in view of the emancipatory, post-modern research designs, which acknowledge subjective knowledge. On account of this, "to embrace Indigenous methodologies is to accept subjective knowledge" (Kovach, 2009, p. 111). Likewise, making the gathering of research data diverse in sources and forms helps to counterbalance the "culturally and racially loaded mechanisms that privilege European epistemological thought" (Kovach, 2009, p. 41). As mentioned above, storytelling is an indigenous methodology in its pictorial and narrative essence due to fact that "in oral tradition, stories can never be decontextualized from the teller" (Kovach, 2009, p. 94), ergo "story is practices within methodologies valuing contextualized knowledge, such as feminism, auto-ethnography, phenomenology, and narrative inquiry" (Kovach, 2009, p. 96). The process of working with data, i.e. processing the findings, conventionally entails the description, analysis, and interpretation; yet due to indigenous critique towards applying the Western analytical lens, the procedure does not always have to tackle coding or grouping, as according to some indigenous researchers and scholars thematic groupings conflict with making meaning holistically, which is a part of the indigenous epistemology (Kovach, 2009, p. 129). The latter, in turn, is a key aspect to be considered when doing research 
with First Nations, or, similarly, in culturally "fragile" environments such as ethnic minority groups subject to marginalization or discriminatory practices (e.g. Roma, religious minorities, refugees, etc.). Furthermore, Smith (1999) argues that reciprocity in research implies establishing ways of collaborating that emphasizes a shared journey, rather than an accumulation of knowledge.

Within the context of European social research it is indeed worthwhile to promote methodology that, while privileging local voices in Indigenist research, focuses on developing dialogic, subjective agendas which can be developed as a community project, social work scheme or educational activities after completing the research. Such an approach and application of indigenous strategies provide concurrently an impetus for responsible and reciprocal forms of relationship established between the researchers and the "researched" community members. It is therefore essential for the research participants to be given a full opportunity to voice their opinions and be involved in the research process throughout the duration of the scheme, applying a "two-eyed way of seeing" research approach (Martin, 2012), and promoting knowledge exchange that could examine current and past assumptions about the researched phenomena (e.g. in case of field research in Bosnia-Herzegovina it can concern Yugonostalgia, Yugoslavian multiculturalism, cross-cultural interactions in the post-war Bosnia, and the like).

Reflections on emic, indigenous research projects are often part of a bigger discussion on the decolonization of science, followed by the critique of Western history, arguing that history is "a modernist project which has developed alongside imperial beliefs about the Other" (Smith, 2012, p. 31). Moreover, indigenous people question the idea that "there is one universal history, or that history is one large chronology, is about development and that it can be told in one coherent narrative" (ibidem). Such arguments used by the aboriginal scholars, or members of indigenous communities, can be also applied in the European context. Namely, as far as the war in Balkans from the beginning of the 1990s is concerned, all of the parties involved (e.g. Bosnian Serbs, Bosnian Croats and Bosnian Muslims) had their own narratives concerning not only the cause and course of the civil war, but also the life in Yugoslavian era proceeding the collapse and leading to this fierce conflict, on the basis of, among others, social injustice, massive inequalities given the ethnic and religious structure, the privileged and underprivileged status of some of the groups, its access to material and non-material resources, etc. Therefore the aim of the research is not to predict (as in positivism), but to understand, emancipate and deconstruct the cultural and social worlds that unfold in front of the researcher while they 
interact with the subjects of the research (Cf. Lather, 1991). Similarly, although the positivist paradigm makes the researcher an "outsider" in the process (making the research design determined by notions of objectivity and neutrality), the critical approaches promote the "insider" stand, such as the emic strategy. Strategy of that kind within participatory research acknowledges two subjects (the researcher and people/individuals she/he wishes to research) of the research, who can be both involved in planning (e.g. negotiating shared concerns which could become the basis of the research question), conducting and interpreting the research (granting the chance to provide different views about a given issue), as well as disseminating the findings. Notwithstanding, the onus is on the researcher to frame, conduct and disseminate the research in a manner that is conducive to the social and cultural values of the people involved. Since "conventional scholars have become formidable gatekeepers of (...) system by objectifying knowledge into criterion-defined models, paradigms, and 'truth"” (Kovach, 2009, p. 79) the emic approach allows the bridging of native and western science. Methodologically, this implies "gathering knowledge that allows for a voice and representational involvement in interpreting findings. Thus, the emic approach can empower the participants and the participant's community in such research projects (p. 82).

The culturally based approach to the research, i.e. the one entailing emic strategies, indigenous methodology and qualitative methods, can in general help social scientists move beyond the binary oppositional discourse of "us versus them". The latter have been prevailing with methods of research serving as (un)aware mechanisms of control and domination. This, in turn, sparked a wider discussion within non-European and non-Western academia on new models of research that can (better) reflect the interests, perspectives, goals, and voices of the researched communities (Rigney, 2001). In her essay "Defining" "Radical Indigenism" and "Creating an American Indian Scholarship" Ewa M. Garroutte (2003) elaborates on Radical Ingienism, yet these remarks can be equally relevant in terms of the culturally sensitive research in Europe: "it will require the participation of scholars who find ways to embed themselves in those communities as contributing members, who can look to traditional knowledge from a position of personal commitment, who can profoundly encounter the sacred stories and songs in a language that generated them, who contribute to conversations that the communities themselves understand to be important, and who make themselves answerable to the rules of conduct and inquiry that govern those communities" (p. 195). Taking this into account, the following principles provide researchers with specific guidance on the appropriate ways to 
get involved in the research process. This, as a consequence, can lead to higher quality and more ethical research that is community driven and reflects the priorities of the local community, relies on collaboration rather than competition and, most importantly, provides mutual benefits to the local communities and researchers, as it is carried out in a more respectful, sympathetic, beneficial and ethical fashion. Such a combination allows the researcher to:

- establish a reliable, ethical and innovative research design that enables the "researched" communities to participate in setting research priorities and guiding research processes (proceeded by getting community consensus about action, i.e. to tackle a problem),

- incorporate a wide range of knowledge and ideas brought to the research,

- encourage input from people at the grassroots level and involve community members,

- make research agenda more responsive to events in the community,

- implement changes which could be beneficial and widely supported by the local communities,

- share and exchange knowledge, skills and experiences.

However, before embarking on such an emic research journey, it is essential for the researcher to reflect on some key issues. From my own experience, in various research projects, the following are the guidelines to consider when working with the culturally fragile.

Critical theory as a framework involves eclectic methodology involving advocacy and constructive paradigms, interpretative and emancipatory in their essence;

1. All research problems must be solved within the context of the culture ${ }^{8}$ as the indigenous adoptee of the emic approach should acknowledge the fact that the cultural and social worlds of investigation are imbued with complexity;

2. The researchers are expected to have a pre-existing and ongoing relationship with participants so that the bond is established before arranging the process of data collection. Such an approach can also allow the researcher to gain more in-depth and idiographic insights, inaccessible to a non-member of a given community and culture;

3. The process of gathering data is personal as well as interpersonal and fully engaging both parties, embracing research circle-talking (cf. Kurtz, 2013), sharing-circles, open-structured methods such as in-depth

\footnotetext{
${ }^{8}$ Otherwise the researcher creates simply another form of assimilation (Bruyere, 1999)
} 
interviews, for the more structured the interview the less flexibility the research participant has in sharing own story;

4. In asking others to share stories, it is vital to share our own, starting with the self, this can be referred to as "self-locating in a research";

5. Participants can review and approve their transcripts; thus it is important to maintain relationships throughout the whole "research journey" (ideally sustained and maintained beyond the project) as in the majority of the research projects the researchers have given very little or nothing back to the people with whom, for instance, they conducted the interviews, who have been, consequently, used as source of information;

6. Due to profound cultural grounding of the research design in a multicultural setting, it is essential to use cultural protocol as a "set of guidelines for interacting with those holders of knowledge whom a researcher seeks out" (Kovach, 2009, p. 127).

7. Cultural sensitivity of a researcher means that even at the stage of choosing research methods researchers shall be aware of the possible repercussions of the whole research project, but also the repercussions of each specific research method they wish to employ in carrying out the project (Weber-Pillwax, 2001, pp. 80-81). Therefore, it is always worth looking for methods that enhance cooperation, collaboration, depend on mutual thinking, give rise to reflection, and spark creativity.

Such procedure within social research is advantageous and rewarding in terms of an approach not to the given research problem but predominantly to the local community, which is at the heart of the matter. It shifts the research design towards constructivism that stems from the thesis of the social construction of the reality. Consequently, the problem occurs secondary to the recognition of the dynamics within a given community, inter-ethnic or cross-cultural relations, the relation of power and dominance, as well as access to various (material and non-material) resources. As a result, the involved attitude of the researcher within collaborative research, brings together different types of expertise (such as community decision makers, health care workers and policy makers) concerning the use of findings, leading to changes in the quality of material, the cultural and mental life of the group functioning on the margin of the mainstream culture. Such a participatory, collaborative and multidisciplinary research design, applying an emic approach and indigenous strategy followed by qualitative methods, provides the researcher with a unique opportunity to bridge different academic traditions, involving a wide (and at times unconventional given the Western academia) range of theoretical perspectives and meth- 
ods, promoting strategies that seek to move cultural considerations from the periphery to the centre of the research arena within European social sciences.

\section{References:}

Atkinson, J. (2002). Trauma Trails, Recreating Song Lines: the Transgenerational Effects of Trauma in Indigenous Australia. Spinifex Press: North Melbourne.

Becker. H. (1967). Whose Side Are We On?. Social Problems, 14/3, pp. 234-247.

Berry, J. (1969). On Cross-cultural Comparability. International Journal of Psychology 4, pp. 119-128.

Berry, J. (1989). Imposed Etics-Emic-Dervied Etics: The Operationalization of a Compelling Idea. International Journal of Psychology, 24, pp. 721-735. DOI: https://doi. org/10.1080/00207598908247841.

Bishop, R. (1999). Collaborative Storytelling: Meeting Indigenous People's Desires for Self-determination. Paper presented at the World Indigenous People's Conference, Albuquerque, NM.

Boas, F. Stocking, G. (1974). The Shaping of American Anthropology, 1883-1911: a Franz Boas Reader. New York: Basic Books.

Boyd, S. (2005). What Knowledge Do You Privilege? Paper presented at Graduate Student Conference for the University of Victoria. Studies in Policy and Practice, Victoria, 18 Nov.

Bruyere, G. (1999). "Empowerment” in Aboriginal Social Work Training Project-Curriculum. Victoria: Caring for First Nations Children Society.

Chilisa, B. (2011). Indigenous Research Methodologies. Los Angeles: Sage.

Christie, M. (2006). Transdisciplinary Research and Aboriginal Knowledge. Australian Journal of Indigenous Education 35, pp.1-12. DOI: https://doi.org/10.1017/ S1326011100004191.

Creswell, J.W. (2003). Research Design: Qualitative, Quantitative, and Mixed Methods Approaches. (2nd ed.) Thousand Oaks: Sage.

Denzin, N.K. and Lincoln, Y.S. (2005) Introduction: The Discipline and Practice of Qualitative Research. In: Denzin N.K., Lincoln, Y. S. (eds.), Handbook of Qualitative Research (pp. 1-32). 3rd Edition. Sage, Thousand Oaks: Sage.

Enriquez, V. (1994). Pagbabangong-dagal: Indigenous Psychology \& Cultural Empowerment. Quezon City: Akademya ng Kultura at Sikolohiyang Pilipino. 


\section{METODY ZBIERANIA I ANALIZY DANYCH W BADANIACH EDUKACYJNYCH}

Enriquez, V. (2006). Developing a Filipino Psychology, In: U. Kim, \& J. W. Berry (eds.), Indigenous Psychology Research and Experience in Cultural Context (pp. 152-169). Newbury Park, CA: Sage Publications.

Fine, J. Van Antwerp (2007). The Bosnian Church : Its Place in State and Society from the Thirteenth to the Fifteenth Century : a New Interpretation. London : Saqi in association with the Bosnian Institute.

Foucault, M. (1997). Discipline and Punish: the Birth of the Prison. Translated by Alan Sheridan. London: Penguin.

Garroutte E.M.(2003). Real Indians: Identity and the Survival of Native America. Berkeley: The University of California Press.

Gergen M., Gergen K.J. (2003). Social Construction: A Reader. Social Construction: A Reader.

Janke, T. (1999). Our Culture: Our Future. Report on Australian Indigenous Cultural and Intellectual Property Rights. Surry Hills: Michael Frankel \& Company.

Kim, U., Triandis H.C., Kagitcibasi C., Choi S-C, \& Yoon G. (eds.) (1994). Individualism and Collectivism: Theory, Method, and Application. Newbury Park, CA: Sage.

Kovach, M. (2009). Indigenous Methodologies: Characteristics, Conversations and Conte$x t s$. Toronto: University of Toronto Press.

Kurtz, D. (2013). Indigenous Methodologies: Traversing Indigenous and Western Worldviews in Research. AlterNative: An International Journal of Indigenous Peoples 9(3), pp. 217-229, DOI: https://doi.org/10.1177/117718011300900303.

Lather, P. (1991). Getting Smart, Feminist Research and Pedagogy with/in the Postmodern. New York: Routledge.

Liamputtong P. (2007). Researching the Vulnerable. A Guide to Sensitive Research Methods. London, Thousand Oaks, New Delhi: Sage Publications.

Martin, D. (2012). Two-eyed Seeing: a Framework for Understanding Indigenous and Non-Indigenous Approaches to Indigenous Health Research. Canadian Journal of Nursing Research 44, pp. 20-42.

Martin, K., Mirraboopa B. (2003). Ways of Knowing, Ways of Being and Ways of Doing: a Theoretical Framework and Methods for Indigenous Research and Indigenist Research. Journal of Australian Studies 76, pp. 203-214, DOI: https://doi. org/10.1080/14443050309387838.

Pe-Pua, R. (2006). From Decolonizing Psychology to the Development of a Cross-Indigenous Perspective in Methodology. In: U. Kim, K-S Yang, \& H. Kwang-Kuo (eds.), Indi- 
genous and Cultural Psychology. International and Cultural Psychology (pp.109-137). New York: Springer.

Pike, K. L. (1954). Language in Relation to a Unified Theory of the Structure of Human Behavior. Dallas, TX, US: Summer Institute of Linguistics.

Pilarska, J. 2015. Interpersonal Skills in Dealing with Multiculturalism : Bosnian Borderland case. EUSER : European Center for Science Education and Research, ICSS Vol. 4, pp. 671-680.

Rigney, D. (2001). The Metaphorical Society: An Invitation to Social Theory. Boston: Rowman \& Littlefield Publishers.

Rigney, L. (1997). Racism and Physical Education: A Critical Indigenist Analysis of the Senate Standing Committee's Report on Physical and Sport Education. Masters of Education Thesis. Adelaide: University of South Australia.

Shweder, R. A. (1991). Thinking through Cultures - Expeditions in Cultural Psychology. Cambridge: Harvard University Press.

Smith L. T. (1999). Decolonizing Methodologies: Research and Indigenous Peoples. London: Zed Books.

Smith, L. (2004). Researching in the Margins: Issues for Mäori Researchers. Paper prepared for the research project, Protocols for Research with Vulnerable and Marginalised Mäori.

Smith, L. (2012). Decolonizing Methodologies. London\&New York: Zed books.

Stewart-Harawira, M. (2005). Cultural Studies, Indigenous Knowledge and Pedagogies of Hope. Policy Futures in Education, 3(2), pp. 153-163, DOI: 10.2304/pfie.2005.3.2.4.

Stocking. G. 1974 (ed.). The Shaping of American Anthropology, 1883-1911: a Franz Boas Reader. New York: Basic Books.

Wallner, F. G. (1997). How to Deal with Science if You Care for Other Cultures. Wien: Braumüller.

Weber-Pillwax, C. (2001). Orality in Northern Cree Indigenous Worlds. Canadian Journal of Native Education, 25(2), pp. 149-165. 